\title{
Array-CGH testing in spontaneous abortions with normal karyotypes
}

\author{
Cleide L. Borovik ${ }^{1}$, Ana Beatriz A. Perez ${ }^{2}$, Luciana R.J. da Silva ${ }^{1,2}$, Ana Cristina V. Krepischi-Santos ${ }^{3}$, \\ Silvia S. Costa $^{3}$ and Carla Rosenberg ${ }^{3}$ \\ ${ }^{1}$ Setor de Genética Laboratorial, Serviço de Técnicas Especiais, Departamento de Patologia Clínica, \\ Hospital Israelita Albert Einstein, São Paulo, SP, Brazil. \\ ${ }^{2}$ Departamento de Morfologia e Pediatria, Centro de Medicina Genética, São Paulo, SP, Brazil. \\ ${ }^{3}$ Departamento de Genética e Biologia Evolucionária, Instituto de Biociências, Universidade de São Paulo, \\ São Paulo, SP, Brazil.
}

\begin{abstract}
In about $50 \%$ of first trimester spontaneous abortion the cause remains undetermined after standard cytogenetic investigation. We evaluated the usefulness of array-CGH in diagnosing chromosome abnormalities in products of conception from first trimester spontaneous abortions. Cell culture was carried out in short- and long-term cultures of 54 specimens and cytogenetic analysis was successful in 49 of them. Cytogenetic abnormalities (numerical and structural) were detected in $22(44.89 \%)$ specimens. Subsequent, array-CGH based on large insert clones spaced at $\sim 1 \mathrm{Mb}$ intervals over the whole genome was used in 17 cases with normal G-banding karyotype. This revealed chromosome aneuplodies in three additional cases, giving a final total of $51 \%$ cases in which an abnormal karyotype was detected. In keeping with other recently published works, this study shows that array-CGH detects abnormalities in a further $\sim 10 \%$ of spontaneous abortion specimens considered to be normal using standard cytogenetic methods. As such, array-CGH technique may present a suitable complementary test to cytogenetic analysis in cases with a normal karyotype.
\end{abstract}

Key words: spontaneous abortion, chromosomal aberrations, array-CGH.

Received: December 3, 2007; Accepted: February 2, 2008.

\section{Introduction}

Numerical chromosome anomalies are the major cause of recognized early gestational loss, with autosomal trisomies being the most frequent and representing about $50 \%$ of all abnormalities, followed by triploidies and monosomy X (Nagaishi et al., 2004; Ljunger et al., 2005). Countless efforts have been made to discover the causes of such cell division errors, particularly in couples presenting recurrence, and several hypotheses to explain them have been proposed (Turleau \& Vekemans, 2005).

The main purpose of performing routine anatomic-pathological examinations in all cases of early abortion is to identify hydatidiform moles, although, from the histological point of view, it is very difficult to distinguish a complete from a partial mole (Lai et al., 2004). Identification of possible fetal malformations responsible for the abortion is generally not possible, because in most cases the material available is maternal decidua and fetal fragments (Fulcheri et al., 2006).

Send correspondence to Cleide Largman Borovik. Laboratório de Genética, Departamento de Patologia Clínica, Hospital Israelita Albert Einstein, R. Ernesto Nazareth 782, 05462-001 São Paulo, SP, Brazil. E-mail: cleide.borovik@gmail.com.
In clinical laboratories routine, cytogenetic analysis is carried out by two methods: short-term culture of chorionic villi and long-term culture. The short-term culture only yields metaphase cells if the sample contains viable cytotrophoblasts, with spontaneous division, usually presenting a lower success rate (Eiben et al., 1990). Long-term cultures generally contain cells both of the fetus and the maternal decidua, and frequently the latter presents preferential growth. Thus, in addition to being a time-consuming test, karyotyping does not always lead to a result; furthermore, in about $4.4 \%$ to $29 \%$ of cases the result does not correspond to the actual fetal karyotype, mainly due to maternal cell contamination as shown by other techniques such as fluorescence in situ hybridization (FISH) and others (Bell et al., 1999; Lomax et al., 2000; Diego-Alvarez et al., 2005; Karaoguz et al., 2005; Nikitina et al., 2005)

DNA-based technologies do not require dividing cells thus, overcoming one of the main limitations associated with conventional cytogenetic analysis of spontaneous abortion material. Several of these methods have been used as diagnostic tools, including fluorescent polymerase chain reaction (Diego-Alvarez et al., 2005), interphase-FISH (Horiuchi et al., 1997; Lebedev et al., 2004, Vorsanova et al., 2005), 
chromosome-CGH (Daniely et al., 1998, Fritz et al., 2001), and multiplex ligation probe amplification (MLPA) (Diego-Alvarez et al., 2006). More recently, array-CGH has been considered as a particularly useful alternative to conventional karyotyping in the field of diagnosis (Schaeffer $e t$ al., 2004; Benkhalifa et al., 2005; Shimokawa et al., 2006), as it allows screening gains and losses in thousands of targets simultaneously. Major advantages of the array-based cytogenetic technologies are the high resolution and high throughput (Salman et al., 2004). It also offers new possibilities for genetic pre-implantation analysis, opening the route toward aneuploidy screening and detection of unbalanced translocations in embryos (Le Caignec et al., 2006).

To evaluate the efficiency of alternative methods for identification of chromosome anomalies in abortion material, we present the results of a study on 49 cases referred for cytogenetic analysis. In 17 of these cases in which the karyotype was normal by conventional analysis we also performed analyzes by a-CGH.

\section{Material and Methods}

\section{Material}

From September, 2005, to May, 2006, 80 products of conceptions (POCs) of first-trimester abortions were referred for cytogenetic analysis on medical request to the Genetics section of the Special Techniques Service of the Clinical Pathology Department of the Hospital Israelita Albert Einstein in São Paulo, Brazil (HIAE).

Initially, informed consent according to the Research Ethics Committees of the HIAE was obtained for 54 cases and a clinical chart was filled out for further research. The cases in which a normal karyotype was found and for which there was still material available were referred for investigation by array-CGH.

The mean maternal age of the entire patient group was $33.52 \pm 4.50$ years (range 23-43). Twenty-nine mothers were primigravidae, and in 14 cases there was at least one previous abortion. Assisted reproduction was reported in only one case.

\section{Cytogenetic analysis}

Whenever the material contained chorionic villi, both short (according to the technique described by Simoni et al., 1983) and long-term culture were set up. If the shortterm culture was successful the karyotype result was based on this analysis. If the short-term culture failed or yielded insufficient material for analysis, the long-term cultures were used. If the material did not contain chorionic villi only long-term cultures were used for analysis. Chromosome analyses were performed after G-banding using Wright stain. A minimum of five, but preferentially 20 cells, were analyzed per sample.

\section{Comparative Genomic Hybridization (array-CGH)}

DNA was extracted from uncultured abortion samples using the QIAmp DNA Mini Kit (Qiagen). Array -CGH was performed as previously described (Rosenberg et al., 2006), using slides containing triplicates of 3,500 BAC/PAC DNA targets spaced at $\sim 1$ Mb intervals, produced at Leiden University Medical Center. As a reference, female DNA was used. Imbalances of the targets were determined based on $\log 2$ intensity ratios of the test/reference sample. A sequence was considered as amplified or deleted when the average $\log 2$ intensity ratio of the replicates was outside the \pm 0.4 range.

\section{Results}

Of the 54 cases referred initially, five (9.26\%) neither yielded metaphases for cytogenetic analysis nor DNA sufficient for array-CGH testing. In 26 cases only short-term cultures were analyzed, in seven cases only long-term cultures, and in 16 cases both types of cultures. Among the latter ones, two showed a discrepancy in the sex complement (in the short-term cultures: 46,XY and in the long-term cultures $46, \mathrm{XX})$. Of the 49 cases in which a cytogenetic result was obtained, $26(53.06 \%)$ had a male chromosome complement and 23 (46.93\%) had a female chromosome complement. Twenty-two (44.89\%) of these 49 cases had an abnormal karyotype: 12 cases showed autosomal trisomy, two cases double autosomal aneuplody, four had triplody, one tetraploidy, two had structural alterations, and one case was $45, X$. In one of the cases with a structural alteration, the chromosome imbalance was found to be inherited from a balanced alteration in the father (Table 1).

Of the 27 cases with a normal karyotype, DNA was extracted from 17 for analysis by the array-CGH technique;

Table 1 - Chromosomal abnormalities detected among 49 first-trimester spontaneous abortions.

\begin{tabular}{|c|c|c|c|c|c|}
\hline \multirow[t]{2}{*}{ Case } & \multicolumn{2}{|c|}{ Cytogenetic analysis karyotype and number of cells } & \multirow[t]{2}{*}{ Array-CGH } & \multirow{2}{*}{$\begin{array}{l}\text { Maternal } \\
\text { age (years) }\end{array}$} & \multirow[t]{2}{*}{ GPA } \\
\hline & Short-term culture & Long-term culture & & & \\
\hline 1 & $69, \mathrm{XXY}[15]$ & NA & NA & 30 & G1P0A1 \\
\hline 2 & $46, X Y[10]$ & NA & $\mathrm{XY}+7$ & 30 & G1P0A1 \\
\hline 3 & $47, \mathrm{XY},+15[4] / 46, \mathrm{XY}[8]$ & NA & NA & 28 & G1P0A1 \\
\hline 4 & $69, \mathrm{XXX}[5]$ & $69, \mathrm{XXX}[5] / 46, \mathrm{XX}[10]$ & NA & 37 & G2P1A1 \\
\hline 5 & NA & $46, \mathrm{XX},[20]$ & $\mathrm{XX}$ & 34 & G2P1A1 \\
\hline 6 & NA & $46, \mathrm{XX},[20]$ & $\mathrm{XX}$ & 43 & G1P0A1 \\
\hline
\end{tabular}


Table 1 (cont.)

\begin{tabular}{|c|c|c|c|c|c|}
\hline \multirow[t]{2}{*}{ Case } & \multicolumn{2}{|c|}{ Cytogenetic analysis karyotype and number of cells } & \multirow[t]{2}{*}{ Array-CGH } & \multirow{2}{*}{$\begin{array}{c}\text { Maternal } \\
\text { age (years) }\end{array}$} & \multirow[t]{2}{*}{ GPA } \\
\hline & Short-term culture & Long-term culture & & & \\
\hline 7 & $46, \mathrm{XX}[5]$ & NA & $\mathrm{XX}$ & 32 & G1P0A1 \\
\hline 8 & $46, X Y[3] / 45, X[3]$ & $47, \mathrm{XY},+?[2] / 46, \mathrm{XY}[7]$ & $\mathrm{XY}+13$ & 43 & $\mathrm{G} 2 \mathrm{P} 0 \mathrm{~A} 2$ \\
\hline 9 & $46, \mathrm{XX}[10]$ & $46, \mathrm{XX}[10]$ & XX & 32 & G1P0A1 \\
\hline 10 & $46, \mathrm{XX}[20]$ & NA & $\mathrm{XX}$ & 32 & $\mathrm{G} 2 \mathrm{P} 1 \mathrm{~A} 1$ \\
\hline 11 & $46, \mathrm{XX}[5]$ & $46, \mathrm{XX}[15]$ & $\mathrm{XX}$ & 38 & G2P1A1 \\
\hline 12 & NA & $47, \mathrm{XY},+22[20]$ & NA & 37 & G1P0A1 \\
\hline 13 & $47, \mathrm{XY},+22[20]$ & NA & NA & 32 & G1P0A1 \\
\hline 14 & $47, \mathrm{XY}+14[2] / 48, \mathrm{XY},+14,+18[17]$ & NA & NA & 40 & G1P0A1 \\
\hline 15 & $48, \mathrm{XY},+8,+21[18]$ & NA & NA & 42 & G4P2A2 \\
\hline 16 & $46, \mathrm{XX}[4]$ & $46, \mathrm{XX}[15]$ & NA & 41 & G3P2A2 \\
\hline 17 & $46, \mathrm{XY}[3] / 45, \mathrm{XY},-3[2] / 45, \mathrm{XY},-15[2]$ & NA & $\mathrm{XY}$ & 29 & G4P0A4 \\
\hline 18 & $46, \mathrm{XX}[17]$ & NA & NA & 33 & G3P2A1 \\
\hline 19 & $46, \mathrm{XY}[20]$ & NA & NA & 31 & G1P0A1 \\
\hline 20 & NA & $46, \mathrm{XX}[20]$ & NA & 34 & G1P0A1 \\
\hline $21^{*}$ & 46,XY[8]/45,XY, -?[2] & $46, X X[9]$ & $\mathrm{XX}$ & 31 & G1P0A1 \\
\hline 22 & $46, \mathrm{XX}[15]$ & NA & NA & 33 & G3P1A2 \\
\hline 23 & $46, \mathrm{XX}[5]$ & $46, \mathrm{XX}[15]$ & NA & 41 & G3P2A2 \\
\hline 24 & NA & $46, \mathrm{XX}[5] / 92, \mathrm{XXXX}[2]$ & $\mathrm{XY}+18$ & 31 & G1P0A1 \\
\hline 25 & $69, \mathrm{XXY}[7] / 46, \mathrm{XY}[2]$ & NA & NA & 40 & $\mathrm{G} 2 \mathrm{P} 0 \mathrm{~A} 2$ \\
\hline 26 & $\mathrm{~F}$ & $\mathrm{~F}$ & NA & 34 & G1P0A1 \\
\hline 27 & $\mathrm{~F}$ & $\mathrm{~F}$ & NA & 29 & G1P0A1 \\
\hline 28 & $47, \mathrm{XY},+16[13]$ & NA & NA & 28 & G1P0A1 \\
\hline 29 & $47, \mathrm{XY},+16[5]$ & $47, \mathrm{XY},+16[15]$ & NA & 30 & G1P0A1 \\
\hline 30 & $46, \mathrm{XY}[3]$ & $46, X Y[17]$ & NA & 29 & G1P0A1 \\
\hline 31 & $\mathrm{~F}$ & $\mathrm{~F}$ & NA & 29 & G1P0A1 \\
\hline 32 & $47, \mathrm{XX},+10[17]$ & NA & NA & 32 & G2P1A1 \\
\hline 33 & $46, \mathrm{XX}[18]$ & NA & NA & 38 & $\mathrm{G} 2 \mathrm{P} 0 \mathrm{~A} 2$ \\
\hline 34 & $46, X Y, \operatorname{DER}(7), t(7 ; 13)(\mathrm{p} 13 ; \mathrm{q} 14[10]$ pat & NA & NA & 28 & G2P1A1 \\
\hline 35 & $46, \mathrm{XX}[16]$ & NA & NA & 23 & G1P0A1 \\
\hline 36 & $46, \mathrm{XY}[9]$ & $46, \mathrm{XY}[2]$ & $\mathrm{XY}$ & 36 & G1P0A1 \\
\hline 37 & $\mathrm{~F}$ & $\mathrm{~F}$ & NA & 35 & G2P1A1 \\
\hline 38 & $\mathrm{~F}$ & $\mathrm{~F}$ & NA & 26 & G1P0A1 \\
\hline 39 & $46, X Y[13]$ & NA & $\mathrm{XY}$ & 36 & G3P1A2 \\
\hline $40^{*}$ & $46, \mathrm{XY}[5]$ & $46, \mathrm{XX}[5]$ & $\mathrm{XY}$ & 33 & G3P1A2 \\
\hline 41 & $47, \mathrm{XY},+16[15]$ & NA & NA & 28 & G1P0A1 \\
\hline 42 & $47, \mathrm{XY},+16[20]$ & NA & NA & 33 & G1P0A1 \\
\hline 43 & $46, \mathrm{XX}[5]$ & $46, \mathrm{XX}[15]$ & NA & 35 & G2P1A1 \\
\hline 44 & $47, \mathrm{XY},+22[7]$ & $47, \mathrm{XY},+22[13]$ & NA & 36 & G3P1A2 \\
\hline 45 & $47, \mathrm{XX},+16[4] / 46, \mathrm{XX}[2]$ & NA & NA & 34 & G1P0A1 \\
\hline 46 & $\begin{array}{l}\text { 46,XY, } \operatorname{idic}(8)(q 10 q 10)[3] / 46, X Y, \operatorname{del}(8) \\
(q 10)[6] / 46, X Y[11]\end{array}$ & NA & NA & 31 & G1P0A1 \\
\hline 47 & $47, \mathrm{XX},+16[15]$ & NA & NA & 34 & $\mathrm{G} 2 \mathrm{P} 0 \mathrm{~A} 2$ \\
\hline 48 & $47, \mathrm{XX},+16[5]$ & $47, \mathrm{XX},+16[15]$ & NA & 31 & G2P1A1 \\
\hline 49 & $69 \mathrm{XXY}[10] / 46, \mathrm{XX}[4]$ & NA & NA & 28 & G1P0A1 \\
\hline 50 & $46, X Y[20]$ & NA & NA & 38 & G1P0A1 \\
\hline 51 & $90, \mathrm{XXXX},-?[2]$ & $46, \mathrm{XX}[10] / 92, \mathrm{XXXX}[4]$ & $\mathrm{XX}$ & 39 & $\mathrm{G} 2 \mathrm{P} 0 \mathrm{~A} 2$ \\
\hline 52 & NA & $46, \mathrm{XX}[20]$ & $\mathrm{XX}$ & 35 & G3P1A2 \\
\hline 53 & $45, \mathrm{X}[6]$ & $45, X[6]$ & NA & 32 & G1P0A1 \\
\hline 54 & $46, X Y[5]$ & NA & $\mathrm{XY}$ & 35 & G2P1A1 \\
\hline
\end{tabular}

$\mathrm{NA}=$ not analyzed $; \mathrm{F}=$ culture failure $; \mathrm{G}=$ Gravity; $\mathrm{P}=$ Parity; $\mathrm{A}=$ Abortion .

*Discrepancies of results obtained by short and long-term cultures. 

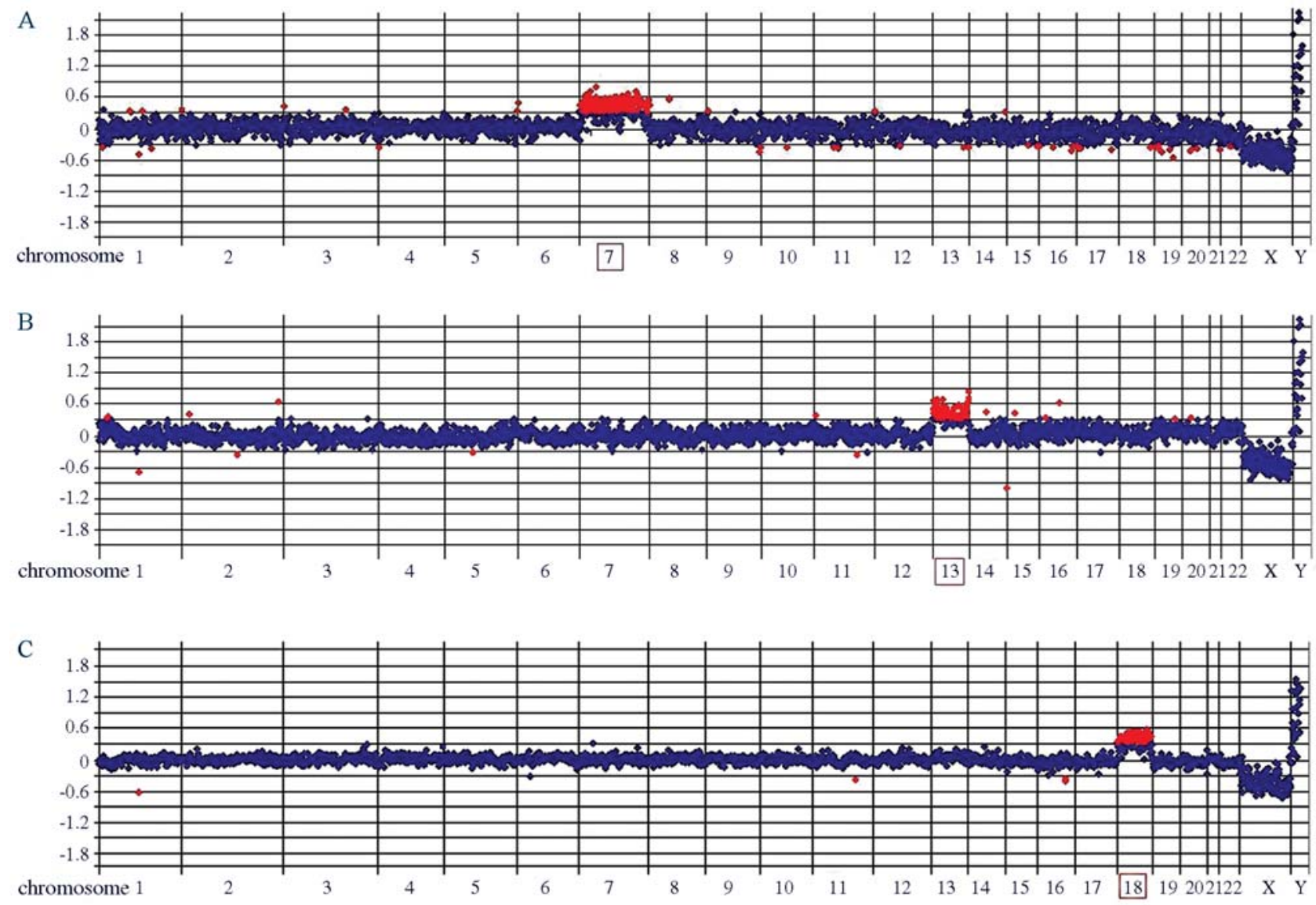

Figure 1 - Whole-genome array-CGH profiles of abortion samples which revealed whole chromosome copy-number changes. The $\mathrm{Y}$ axis is log ratio of the test/ reference DNAs intensities, and the $\mathrm{X}$ axis displays the whole-genome profile for ordered by chromosome from 1 to $22, \mathrm{X}$ and $\mathrm{Y}$, and from $\mathrm{p}$ to $\mathrm{q}$ arm. Genomic sequences with significantly increased or decreased copy number are represented by red dots, illustrating a gain of chromosome 7 (A), chromosome 13 (B) and chromosome 18 (C). The three cases are XY and were hybridized against female DNA, resulting the observed imbalances for the sex chromosomes.

from the other 10 cases with a normal karyotype no suitable material was available. In three of the 17 cases analyzed by array-CGH, chromosome alterations that had gone undetected were found: one trisomy 7, one trisomy 13 and one trisomy 18 (Figure 1). Discrepancy in the sex complement was detected in two cases: in the one with trisomy 18 and in one with a normal karyotype (Table 1).

Thus, $51 \%$ of the cases in which a result was obtained showed chromosomal alterations.

The results of the anatomic-pathological examination showed hydropic degeneration of the chorionic villi to a greater or lesser extent in 13 cases: one with a 46,XX karyotype, five $46, \mathrm{XY}$, five with trisomy of chromosome 16 , and two with triploidy.

\section{Discussion}

Chromosome abnormalities detected by conventional karyotyping have been described in abortion material for a long time now. However, this material is often unsuitable for analysis with reliable results, either due to its poor qual- ity or the small number of cells obtained in culture (Danielly et al., 1998; Lomax et al., 2000; Greenwold and Jauniaux, 2002).

In an attempt to overcome these problems other techniques such as fluorescent polymerase chain reaction (Diego-Alvarez et al., 2005), interphase-FISH (Horiuchi et al., 1997; Lebedev et al., 2004, Vorsanova et al., 2005), chromosome-CGH (Daniely et al., 1998; Fritz et al., 2001), MLPA (Diego-Alvarez et al., 2006) and array-CGH have been introduced in the study of POCs.

To our best knowledge, there are so far three published studies using the array-CGH technique in abortion material. Schaeffer et al. (2004) examined 41 POC samples by a $1 \mathrm{Mb}$ resolution array-CGH, and compared the results with those obtained by G-band analysis. In this study, 37/41 POC cases were in exact concordance with the karyotype results. Moreover, the array identified additional anomalies that had not been detected by routine chromosome analysis, in the four remaining cases: a clone with trisomy 20 , besides non-mosaic trisomy 21 ; an interstitial microdeletion 
of chromosome $9 \mathrm{p}$ in addition to trisomy 13; an interstial microduplication of chromosome 15 in addition to trisomy 16; and a submicroscopic duplication of chromosome 10 long arm. Benkhalifa et al. (2005) studied 26 samples of abortion material with no growth. They found 12 cases with numerical anomalies and two with possible submicroscopic anomalies. Shimokawa et al. (2006) analyzed 20 POC samples with normal karyotype and identified two cases with microdeletions. These studies show that POC material can be analyzed by array-CGH, and that it can detect additional alterations when compared to classical cytogenetics.

In the present study we employed an array with 3,500 BAC/PAC DNA targets spaced at $\sim 1 \mathrm{Mb}$ intervals and identified aneuploidies in three cases in which conventional cytogenetic analysis had shown a normal karyotype. In two cases in which a normal male karyotype $(46, X Y)$ had been found, array-CGH revealed the presence of an additional chromosome 7 in one of them and of an additional chromosome 13 in the other. Although the presence of an undetected mosaicism cannot be ruled out, considering that the presence of mosaicism is a rather frequent finding in abortion material (Lebedev et al. 2004; Schaeffer et al., 2004; Vorsanova et al. 2005), it is also possible that it went undetected by the conventional cytogenetic analysis because of the previously mentioned difficulties usually presented by abortion material. In the third case in which conventional analysis of cells from a long term culture revealed a 46,XX karyotype and the array-CGH analysis showed a male complement with an additional chromosome 18 , very likely the analyzed cells were of maternal origin.

In one case in our study the cytogenetic analysis based on a short-term culture was $46, \mathrm{XY}$ but the array revealed a female DNA. It is possible that the extracted DNA was mainly of maternal origin, once the karyotype from the long-term culture was 46,XX.

After applying the array-CGH technique, the overall rate of detected chromosome abnormalities was $51 \%$. This figure is similar to the frequency of chromosome aberrations usually reported in the literature. Complementarily, if only array-CGH had been performed, probably all alterations except the ploidy changes would have been detected. Although the array-CGH technique is not a suitable tool for detecting ploidy changes, Ballif et al. (2006) described the use of a control DNA of a Klinefelter individual as an approach to identify possible ploidy alterations. All papers in the literature on studies using complementary techniques to cytogenetic analysis showed that the contribution of chromosome anomalies to first-trimester fetal losses is much greater than found by conventional cytogenetic analysis, being estimated in up to $70 \%$ (Fritz et al., 2001). For instance, when Daniely et al. (1998) used chromosome-CGH in cases in which the karyotype found by cytogenetics was normal or could not be obtained due to culture failure, they detected additional numerical and structural anomalies in $8 \%$ of the POC from couples with recurrent abortions.

In the present study, trisomy of chromosome 16 was predominant, followed by triploidy and trisomy 22 . Trisomy 16 is the most frequently encountered trisomy in early abortion specimens, presenting an incidence of $\sim 1.5 \%$ of all clinically recognized gestations. Most of these embryos undergo spontaneous abortion or a developmental arrest between the $8^{\text {th }}$ and $15^{\text {th }}$ weeks (Yong et al., 2003).

Double trisomy was detected in two cases of our sample (4.08\%). In both of them, maternal age was high (40 and 42 years), supporting the implication of a maternal agerelated mechanism, as previously reported (Reddy, 1997; Diego-Alvarez et al., 2006).

In two of our cases, structural anomalies were detected. In one of them, the father carried the balanced form of a $t(7 ; 13)$ translocation. The gestational history revealed a previous abortion and a normal child. However, there was a history of multiple fetal losses in the paternal grandmother and great-grandmother, suggesting that the translocation may be segregating in the family for some generations. In the other case it was not possible to obtain the parental karyotypes, but the kind of alteration found, ie, a mosaicism involving an idic(8), a del(8) and a normal karyotype suggests that the events were not inherited.

Triploidy occurs in approximately $2 \%$ of conceptuses. Its occurrence is not associated with an increase in maternal age, but whenever the additional chromosome complement is of paternal origin, the placenta exhibits histological characteristics of a partial hydatidiform mole (Brancati et al., 2003). In fact, in one of the cases with triploid karyotype, in which the anatomic-pathological study showed hydropic degeneration of the villi, we were able to demonstrate the paternal origin of the additional chromosome complement (data not shown).

The anatomic-pathological findings show that hydropic degeneration of villi is not a feature exclusive of hydatidiform moles (complete or partial). Although half of the cases in which it was observed presented a chromosome alteration, inferences regarding the karyotype based on pathological examination should be avoided (Lescoat et al., 2005).

The data of abortion investigations reported so far show an encouraging picture as to the applicability of array-CGH, at least as a complementary method to the traditional cytogenetic techniques. The results of the present study, confirm that the use of array-CGH to complement classical cytogenetics in the chromosome analyses of abortion material is highly recommended.

\section{Acknowledgments}

This work was supported by FAPESP and CNPq. The authors thank Nicole S. L.Grosso for reviewing the manuscript. 


\section{References}

Ballif BC, Kashork CD, Saleki R, Rorem E, Sundin K, Bejjani BA and Shaffer LG (2006) Detecting sex chromosome anomalies and common triploidies in products of conception by array-based comparative genomic hybridization. Prenat Diagn 26:333-339.

Bell KA, Van Deerlin PG, Haddad BR and Feinberg RF (1999) Cytogenetic diagnosis of "normal 46,XX" karyotypes in spontaneous abortions frequently may be misleading. Fertil Steril 71:334-341.

Benkhalifa M, Kasakyan S, Clement P, Baldi M, Tachdjian G, Demirol A, Gurgan T, Fiorentino F, Mohammed M and Qumsiyeh MB (2005) Array comparative genomic hybridization profiling of first-trimester spontaneous abortions that fail to grow in vitro. Prenat Diagn 25:894-900.

Brancati F, Mingarelli R and Dallapiccola B (2003) Recurrent triploidy of maternal origin. Eur J Hum Genet 11:972-974.

Daniely M, Aviram-Goldring A, Barkai G and Goldman B (1998) Detection of chromosomal aberration in fetuses arising from recurrent spontaneous abortion by comparative genomic hybridization. Hum Reprod 13:805-809.

Diego-Alvarez D, Garcia-Hoyos M, Trujillo MJ, Gonzalez-Gonzalez C, Rodriguez de Alba M, Ayuso C, Ramos-Corrales C and Lorda-Sanchez I (2005) Application of quantitative fluorescent PCR with short tandem repeat markers to the study of aneuploidies in spontaneous miscarriages. Hum Reprod 20:1235-1243.

Diego-Alvarez D, Ramos-Corrales C, Garcia-Hoyos M, Bustamante-Aragones A, Cantalapiedra D, Diaz-Recasens J, Vallespin-Garcia E, Ayuso C and Lorda-Sanchez I (2006) Double trisomy in spontaneous miscarriages: Cytogenetic and molecular approach. Hum Reprod 21:958-966.

Eiben B, Bartels I, Bahr-Porsch S, Borgmann S, Gatz G, Gellert G, Goebel R, Hammans W, Hentemann M and Osmers R (1990) Cytogenetic analysis of 750 spontaneous abortions with the direct-preparation method of chorionic villi and its implications for studying genetic causes of pregnancy wastage. Am J Hum Genet 47:656-663.

Fritz B, Hallermann C, Olert J, Fuchs B, Bruns M, Aslan M, Schmidt S, Coerdt W, Muntefering H and Rehder H (2001) Cytogenetic analyses of culture failures by comparative genomic hybridisation (CGH)-Re-evaluation of chromosome aberration rates in early spontaneous abortions. Eur J Hum Genet 9:539-547.

Fulcheri E, Bulfamante G, Resta L and Taddei GL (2006) L'embrio-patologia e la patologia feto-perinatale nella diagnostica anatomo-patologica: Cosa è cambiato e cosa è necessario cambiare. Pathologica 98:1-36 (Abstract in English).

Greenwold N and Jauniaux E (2002) Collection of villous tissue under ultrasound guidance to improve the cytogenetic study of early pregnancy failure. Hum Reprod 17:452-456.

Horiuchi I, Hashimoto T, Tsuji Y, Shimada H, Furuyama J and Koyama K (1997) Direct assessment of triploid cells in mosaic human fetuses by fluorescence in-situ hybridization. Mol Hum Reprod 3:445-450.

Karaoguz MY, Nas T, Konac E, Ince D, Pala E and Menevse S (2005) Is cytogenetic diagnosis of 46,XX karyotype spontaneous abortion specimens erroneous? Fluorescence in situ hybridization as a confirmatory technique. J Obstet Gynaecol Res 31:508-513.
Lai CYL, Chan KYK, Khoo US, Ngan HYS, Xue WC, Chiu PM, Tsao SW and Cheung ANY (2004) Analysis of gestational trophoblastic disease by genotyping and chromosome in situ hybridization. Mod Pathol 17:40-48.

Le Caignec C, Spits C, Sermon K, De Rycke M, Thienpont B, Debrock S, Staessen C, Moreau Y, Fryns JP, Van Steirteghem A, et al. (2006) Single-cell chromosomal imbalances detection by array CGH. Nucleic Acids Res 34:e68.

Lebedev IN, Ostroverkhova NV, Nikitina TV, Sukhanova NN and Nazarenko SA (2004) Features of chromosomal abnormalities in spontaneous abortion cell culture failures detected by interphase FISH analysis. Eur J Hum Genet 12:513-520.

Lescoat D, Jouan H, Loeuillet-Olivo L and Le Calve M (2005) Fluorescent in situ hybridization (FISH) on paraffinembedded placental tissues as an adjunct for understanding the etiology of early spontaneous abortion. Prenat Diagn 25:314-317.

Ljunger E, Cnattingius S, Lundin C and Anneren G (2005) Chromosomal anomalies in first-trimester miscarriages. Acta Obstet Gynecol Scand 84:1103-1107.

Lomax B, Tang S, Separovic E, Phillips D, Hillard E, Thomson T and Kalousek DK (2000) Comparative genomic hybridization in combination with flow cytometry improves results of cytogenetic analysis of spontaneous abortions. Am J Hum Genet 66:1516-1521.

Nagaishi M, Yamamoto T, Iinuma K, Shimomura K, Berend SA and Knops J (2004) Chromosome abnormalities identified in 347 spontaneous abortions collected in Japan. J Obstet Gynaecol Res 30:237-241.

Nikitina TV, Lebedev IN, Sukhanova NN, Sazhenova EA and Nazarenko SA (2005) A mathematical model for evaluation of maternal cell contamination in cultured cells from spontaneous abortions: Significance for cytogenetic analysis of prenatal selection factors. Fertil Steril 83:964-972.

Reddy KS (1997) Double trisomy in spontaneous abortions. Hum Genet 101:339-345.

Rosenberg C, Knijnenburg J, Bakker E, Vianna-Morgante AM, Sloos W, Otto PA, Kriek M, Hansson K, Krepischi-Santos AC, Fiegler H, et al. (2006) Array-CGH detection of micro rearrangements in mentally retarded individuals: Clinical significance of imbalances present both in affected children and normal parents. J Med Genet 43:180-186.

Salman M, Jhanwar SC and Ostrer H (2004) Will the new cytogenetics replace the old cytogenetics? Clin Genet 66:265-275.

Schaeffer AJ, Chung J, Heretis K, Wong A, Ledbetter DH and Lese MC (2004) Comparative genomic hybridization-array analysis enhances the detection of aneuploidies and submicroscopic imbalances in spontaneous miscarriages. Am J Hum Genet 74:1168-1174.

Shimokawa O, Harada N, Miyake N, Satoh K, Mizuguchi T, Niikawa N and Matsumoto N (2006) Array comparative genomic hybridization analysis in first-trimester spontaneous abortions with 'normal' karyotypes. Am J Med Genet A 140:1931-1935.

Simoni G, Brambati B, Danesino C, Rossella F, Terzoli GL, Ferrari M and Fraccaro M (1983) Efficient direct chromosome analyses and enzyme determinations from chorionic villi samples in the first trimester of pregnancy. Hum Genet 63:349-357. 
Turleau C and Vekemans M (2005) Nouvelles données en génétique chromosomique. Med Sci 21:940-946 (Abstract in English).

Vorsanova SG, Kolotii AD, Iourov IY, Monakhov VV, Kirillova EA, Soloviev IV and Yurov YB (2005) Evidence for high frequency of chromosomal mosaicism in spontaneous abortions revealed by interphase FISH analysis. J Histochem Cytochem 53:375-380.
Yong PJ, Barrett IJ, Kalousek DK and Robinson WP (2003) Clinical aspects, prenatal diagnosis, and pathogenesis of trisomy 16 mosaicism. J Med Genet 40:175-182.

Associate Editor: John M. Opitz

License information: This is an open-access article distributed under the terms of the Creative Commons Attribution License, which permits unrestricted use, distribution, and reproduction in any medium, provided the original work is properly cited. 